\title{
Mitigating Friction in Multicultural VIRTUAL ORGANIZATIONS / TEAMS
}

\author{
Ionut Savu, Cicerone Laurentiu Popa \& Costel Emil Cotet
}
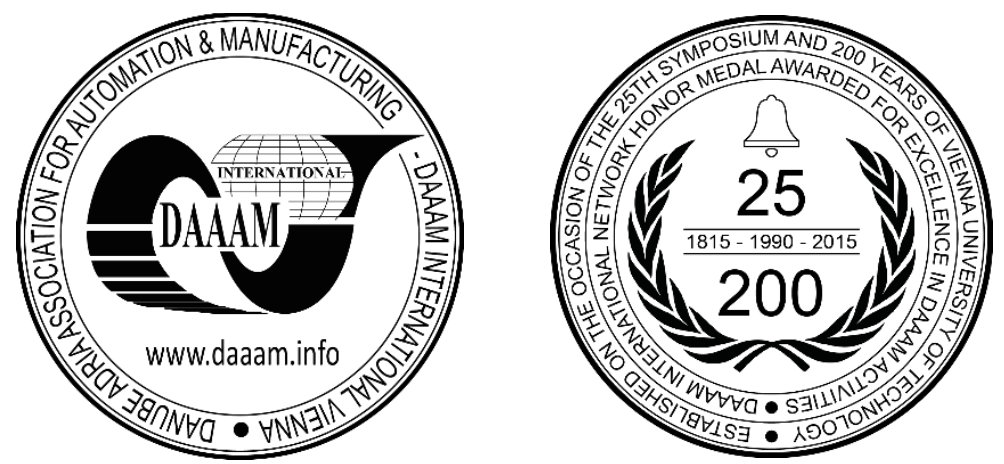

This Publication has to be referred as: Savu, I[onut]; Popa, C[icerone] L[aurentiu] \& Cotet, C[ostel] E[mil] (2017). Mitigating Friction in Multicultural Virtual Organizations / Teams, Proceedings of the 28th DAAAM International Symposium, pp.0737-0742, B. Katalinic (Ed.), Published by DAAAM International, ISBN 978-3-902734-11-2, ISSN 1726-9679, Vienna, Austria

DOI: $10.2507 / 28$ th.daaam.proceedings.104

\begin{abstract}
In an increasingly global marketplace, the rise and fall of actors that want to compete on the world stage has become dependent on their ability to search for and find creative solutions to a fast paced and changing market. This search for fast problem solving, plasticity of ideas and increased efficiency has more often than not lead to creation of virtual teams and organizations, some spanning several countries, mindsets and cultures. By describing the problems arisen in working in a multinational company that tries to apply local values to a global workspace and the corresponding solutions found, this paper aims to find general guidelines by which friction in communication could be reduced to better facilitate efficiency in multicultural virtual teams as well as discover what principles should be applied for better remote management. This article leverages research done in anthropological studies of intercultural cooperation to contextualize the issues at hand in the behaviour of team members and managers in a virtual space.
\end{abstract}

Keywords: Virtual organizations; Multiculturalism; Virtual teams; Communication; Efficiency

\section{Introduction}

Organizations are currently facing important and unprecedented challenges in an ever dynamic, constantly changing and complex environment [1]. Economic activity of all types is moving in the direction of globalization [2][3]. With the rapid development of electronic information and communication media in the last decades, distributed work has become much easier, faster and more efficient [4]. To respond to the increasing de-centralization and globalization of work processes, many organizations have adapted to these dynamic environments by introducing virtual teams that collaborate by communication technologies across geographical, temporal, cultural and organizational boundaries to achieve common goal in their organization's outputs. Virtual teams are growing in popularity and the rapid development of new communication technologies such as the internet has accelerated this trend so that today, most of the larger organizations employ virtual teams to some degree [4]. Information technology is providing the infrastructure necessary to support the development of new forms of organizations. Virtual teams represent one such form, one that could revolutionize the workplace and provide organizations with unprecedented level of flexibility and responsiveness [5]. Virtual teams are important mechanisms for those seeking to leverage scarce resources across geographic and other boundaries [6] and represent a large pool of new product know-how which seems to be a promising source of innovation. With the rise of 
globalization, virtual teams are more distributed than ever, across time, space, and culture. These dimensions correspond to challenges that can significantly impact the productivity of virtual teams and the quality of the inter-personal relationships of their members. By describing the problems arisen in working in a multinational company that tries to apply local values to a global workspace and the corresponding solutions found, this paper aims to find general guidelines by which friction in communication could be reduced to better facilitate efficiency in multicultural virtual teams as well as discover what principles should be applied for better remote management.

\section{Historical Context}

For a complete understanding of virtual teams we have to take into account the historical context of their development as a result of globalization. Hertel et al. viewed it as the free movement of goods, capital, services, people, technology and information across the world, the action or procedure of international integration of countries arising from the convergence of world views, products, ideas, and other aspects of culture [7]. Advances in means of transport (such as the steam locomotive, steamship, jet engine, and container ships) and in telecommunications infrastructure have been major factors in globalization, generating further interdependence of economic and cultural activities [8][9]. Large-scale globalization began in the 1820s [10]. In the late 19th century and early 20th century, the connectivity of the world's economies and cultures grew rapidly. During the 19th century, globalization approached its form as a direct result of the Industrial Revolution which allowed standardized production of household items using economies of scale while rapid population growth created sustained demand for commodities. Also, steamships reduced the cost of international transport significantly and railroads made inland transport cheaper. More nations embraced international trade [10] and the invention of shipping containers in 1956 also helped advance the globalization of commerce [11]. Student exchange programs became popular after World War II, and were intended to increase the participants' understanding and tolerance of other cultures, as well as improving their language skills and broadening their social horizons. Between 1963 and 2006 the number of students studying in a foreign country increased 9 times [12]. The emergence of the virtual workplace has been tightly linked to the fast increase of PC sales in the 1960s, the popularity of cellular phones in the 1970s, the internet and the World Wide Web in the 1990s. Thus necessity, economic and technological viability had merged to make the concept of virtual teams a reality.

\section{Virtual Teams}

Virtual teams are the group of individuals united by a common goal but spread geographically, culturally, linguistically or, ethnically. As defined by Powell, Piccoli and Ives, virtual teams are described 'as groups of geographically, organizationally and/or time dispersed workers brought together by information and telecommunication technologies to accomplish one or more organizational tasks'. Virtual teams mainly meet the demand for flexibility and agility in the delivery of services or products in a marketplace with increased competition and a decentralized and globalized work processes. The need for talent and competency has lead organizations to look to structures which leverage available talent across boundaries. More and more organizations are adopting virtual team approach to reduce their operating costs, encourage knowledge sharing among their employees to promote organizational learning and expand their business hours to $24 / 7$ by utilizing the different time zones of virtual team members [13]. Human relationships draw their power from the proximity of the individuals but due to the fact that virtual team members have limited personal interaction this creates a myriad of issues. For a virtual team to be productive it is important to overcome the cultural differences, communication barriers, power struggles and conflict to build trust, collaboration and commitment among the individuals. By using the right strategies, tools and processes, organizations can benefit greatly from this new-age trend of virtual teams [13].

\section{Types of Virtual Teams}

Virtual teams can be classified into 6 categories depending on lifespan, temporal distribution, role of members and objectives.

\section{Networked Teams:}

They are short-lived and serve the function of resolving a short-term objective. Team members are sometimes brought from outside the organization to share their expertise as cross-functional participants and for their broader perspective. Networked teams, upon completion of their objectives are dismissed thus, their lifespan varies on how complex the issue at hand is.

\section{Parallel Teams:}

They are highly task oriented teams that usually consist of specialized professionals. While they are generally only required for very short span of time, unlike networked teams, they are not dissolved after completion of the tasks. The team may be either internal or external to the organization [14].

\section{Project or Product Development Teams:}

These were actually the pioneer in the development of virtual teams. They work on complex sets of activities, are composed of subject matter experts brought together from different parts of the globe, over a long time period and may be formed to develop new products, deliver a new technology system, or redesign operational processes. 


\section{Work, Production or Functional Teams:}

They are formed when members with specific skill sets come together to perform a single type of ongoing activity. These teams are totally function specific as they only work on a particular area within an organization. Operating virtually from different geographical locations, these teams exist to perform regular or ongoing tasks.

\section{Service Teams:}

Service teams are geographically located in different time-zones and are assigned to a particular service such as customer support to provide 24/7 continuity. Though each member works independently, they together perform work in continuation. This kind of team also has value in technical support activities

\section{Offshore ISD Teams:}

They are independent service provider teams that a company can subcontract portions of work to. This is the model that is most used in outsourcing organizations, especially software development or R\&D. The team is usually based in a low-cost location and coordinates with the onshore team to deliver the expected results.

\section{Advantages and Disadvantages of Virtual Teams}

Regarding the advantages and disadvantages of virtual teams we can contextualize them from three perspectives, individual, organizational and societal. The table below summarizes the attribute, positive and negative, of virtual teams so that a clear pathway to identifying constructive solutions can be uncovered.

\begin{tabular}{|c|c|}
\hline Advantages & Disadvantages \\
\hline $\begin{array}{l}\text { Cost savings } \\
\text { Organizations can optimize real estate costs by using } \\
\text { virtual teams as well as utility or travel expenses. Most } \\
\text { outsource operations in low-cost regions to also take } \\
\text { advantage of lower wages of the employees. }\end{array}$ & $\begin{array}{l}\text { Cost of Technology } \\
\text { One of the main costs in running virtual teams comes } \\
\text { from the necessary technology required to run them. } \\
\text { Without the use of multiple communication technologies } \\
\text { it is either impossible or impractical to run such teams. }\end{array}$ \\
\hline $\begin{array}{l}\text { Global Talent } \\
\text { By leveraging human capital from around the world, } \\
\text { organizations can bring in the fold greater understanding } \\
\text { of local markets as well as benefit from specialist and } \\
\text { experts that increase innovation and knowledge sharing. }\end{array}$ & $\begin{array}{l}\text { Conflicts, Lack of Trust \& Collaboration } \\
\text { One of the main reasons for conflict in virtual teams is } \\
\text { the cultural divide as well as the different styles of } \\
\text { communication which give rise to mistrust and } \\
\text { difficulties in collaboration that are intrinsic to their } \\
\text { success. Other challenges come from the lack of direct } \\
\text { interaction as most communication is done through non- } \\
\text { verbal interactions. }\end{array}$ \\
\hline $\begin{array}{l}\text { Increased Productivity } \\
\text { As opposed to local teams, virtual teams tend to have a } \\
\text { greater focus on the objectives dealt with as they benefit } \\
\text { from a flatter structure of organization. This translates } \\
\text { into increased productivity and greater profits for the } \\
\text { company. }\end{array}$ & $\begin{array}{l}\text { Social Isolation } \\
\text { Although collaboration in the virtual space has many } \\
\text { advantages, on a personal level, the lack of direct contact } \\
\text { with coworkers may lead to an adverse affect on the } \\
\text { psychological welfare of team members and consequently } \\
\text { on productivity. }\end{array}$ \\
\hline \multicolumn{2}{|l|}{$\begin{array}{l}\text { Decreased Time to Market } \\
\text { Virtual teams can leverage the different time zones that } \\
\text { the members span and run the project continuously } 24 / 7 \text {. } \\
\text { This greatly speeds up development as well as response } \\
\text { time. }\end{array}$} \\
\hline $\begin{array}{l}\text { New Opportunities } \\
\text { Any tasks that do not require physical presence are now } \\
\text { obtainable by candidates that formerly were restricted by } \\
\text { availability thus opening the doors to new potential talent. }\end{array}$ & \\
\hline
\end{tabular}

Table 1. Advantages \& Disadvantages of Virtual Teams [15]

Although challenges clearly exist in implementing a successful virtual team, these can be overcome by following more efficient communication strategies that take into account the cultural makeup of the team as well as following different leadership strategies. 


\section{Case Study and Anthropological Context}

Through research it has been documented that the success of multicultural teams is vital for the performance of organizations [16][17]. In the context of virtual teams and increased contact with multiculturalism, interest has been renewed in understanding and developing communication skills that are needed for high performing cross cultural teams. In a study by Matveev and Nelson (2004) [18] there was found a significant effect of national culture on cross-cultural communication competence, suggesting the need to train managers to become more effective in culturally complex workplaces. National culture of team members plays a significant role in determining whether communicative behavior is perceived as competent, thus emphasizing the central role that national culture and ethnicity play in assessing communication competence already documented in the literature [19][20][21]. For companies that leverage virtual teams, their performance becomes vulnerable to cross-cultural problems [18]. Managing cultural diversity, cultural differences, and cross-cultural conflicts have surfaced as frequent challenges for cross-cultural teams [22].

Matveev and Nelson (2004) emphasize five cultural orientations that could influence cross-cultural communication competence: long term orientation, power distance, individualism, uncertainty avoidance, and performance orientations [22].

The intent of this study was to document the points of failure and success in the studied virtual team and draw a correlation with the cultural orientation of the members involved, drawing from prior research done in anthropological studies of cross-cultural interactions. To do so, a secondary analysis was done, using data from Hofstede's 6-D Model of cultural overview. The team was composed of 13 members from Finland, Serbia, Switzerland, Denmark, Sweden, Poland and Romania with management and IT support done by israeli members. It can be characterized as a functional team as it came together to provide account development services for the business clients of the company.

The table below presents the characteristics of each of the team members' native cultures.

\begin{tabular}{|c|c|c|c|c|c|}
\hline & $\begin{array}{c}\text { Long term } \\
\text { orientation }\end{array}$ & Power Distance & Individualism & $\begin{array}{c}\text { Uncertainty } \\
\text { Avoidance }\end{array}$ & $\begin{array}{c}\text { Performance } \\
\text { Orientations }\end{array}$ \\
\hline Finland & 38 & 33 & 63 & 59 & 26 \\
\hline Serbia & 52 & 86 & 25 & 92 & 43 \\
\hline Switzerland & 74 & 34 & 68 & 58 & 70 \\
\hline Denmark & 35 & 18 & 74 & 23 & 16 \\
\hline Sweden & 53 & 31 & 71 & 29 & 5 \\
\hline Poland & 38 & 68 & 60 & 93 & 64 \\
\hline Romania & 52 & 90 & 30 & 90 & 42 \\
\hline Israel & 38 & 13 & 54 & 81 & 47 \\
\hline
\end{tabular}

Table 2. Cultural Orientation Score [23]

Long term orientation describes how every society has to maintain some links with its own past while dealing with the challenges of the present and future, and societies prioritise these two existential goals differently. Normative societies which score low on this dimension, for example, prefer to maintain time-honoured traditions and norms while viewing societal change with suspicion. Those with a culture which scores high, on the other hand, take a more pragmatic approach: they encourage thrift and efforts in modern education as a way to prepare for the future [23].

Power distance deals with the fact that all individuals in societies are not equal - it expresses the attitude of the culture towards these inequalities amongst us. Power Distance is defined as the extent to which the less powerful members of institutions and organisations within a country expect and accept that power is distributed unequally [23].

Individualism is the degree of interdependence a society maintains among its members. It has to do with whether people's self-image is defined in terms of "I" or "We". In Individualist societies people are supposed to look after themselves and their direct family only. In Collectivist societies people belong to 'in groups' that take care of them in exchange for loyalty [23].

Uncertainty Avoidance has to do with the way that a society deals with the fact that the future can never be known: should we try to control the future or just let it happen? This ambiguity brings with it anxiety and different cultures have learnt to deal with this anxiety in different ways. The extent to which the members of a culture feel threatened by ambiguous or unknown situations and have created beliefs and institutions that try to avoid these is reflected in the score on Uncertainty Avoidance [23]. 
Performance Orientations A high score on this dimension indicates that the society will be driven by competition, achievement and success, with success being defined by the winner/best in field - a value system that starts in school and continues throughout organisational life. A low score on the dimension means that the dominant values in society are caring for others and quality of life. The fundamental issue here is what motivates people, wanting to be the best or liking what you do [23].

Going forward we report on the successful interactions and some of the main problems observed in the studied virtual team and interpret through the lens of the stated cultural dimensions.

\section{Lack of Differential Treatment to the Complexity of Virtual Teams}

Organizations have a tendency to not differentiate between virtual and traditional teams thus not taking into account the complexity of virtual teams in regard to time, distance and cultural differences. There is no specialized training imparted to either team members nor team leaders. The particular case studied manifested friction especially between management and team members from Romania, Serbia and to some extent Poland. A sentiment of weak management style was developed. This is evidence of the difference in the power distance index between the parties. In Israel power is decentralized, managers count on the experience of their team members and employees expect to be consulted whereas the others accept a hierarchical order in which everybody has a place and which needs no further justification. Hierarchy in an organization is seen as reflecting inherent inequalities, centralization is popular, subordinates expect to be told what to do and the ideal boss is a benevolent autocrat [23].

\section{Ambiguity towards Responsibility and Task}

Due to the reliance on virtual communication and lack of face to face contact, a lack of clarity emerges towards the specific role a member has. Moreover since most communication within the team is process oriented working relationships are difficult to develop which affects information sharing and trust. Again this issue manifested mainly in team members from countries with high power distance index but less in polish members. We speculate this is because of their high level of individualism.

\section{Leadership}

As stated formerly, virtual teams rely heavily on modern communication technology thus the absence of face to face contact needs to be addressed [24]. To compensate for the particularities of managing a virtual team, leaders need to incorporate technical abilities as well as interpersonal and team building aptitudes into their skillset. In the studied virtual team, the leaders managed to compensate the downfalls of the virtual communication medium by having a more involved attitude towards the team members [26][27]. Low power distance and a high uncertainty avoidance score is indicative of this cultural inclination. There is an emotional need for rules, people have an inner urge to be busy and work hard, precision and punctuality are the norm, security is an important element in individual motivation [23]. Cultures with a high score on this dimension are often very expressive.

\section{Lack of Trust}

The socialization process intrinsic to the development of trust in a team is absent in the virtual team environment [25]. Lack of trust at the level of either the team member or the team leader results in low relational commitment and conflicts evident in low productivity and performance of the team. The main issues observed were in cases where close collaboration was needed between members of Denmark/Sweden and Romania/Serbia/ Poland. The high delta of uncertainty avoidance between northern and eastern european cultures could be a factor. Whereas countries exhibiting high uncertainty avoidance index (UAI) maintain rigid codes of belief and behaviour and are intolerant of unorthodox behaviour and ideas, low UAI societies maintain a more relaxed attitude [23].

\section{Lack of Effective Communication}

Since there is a lack of nonverbal cues which are central to trust building, issues might arise that affect performance. Although modern communication tools as emails, video conferencing, instant messaging, phone are being used they do not convey information at all levels. Even though eventually mitigated by team building exercises, communication between team members from cultures with polarised individualism indexes was lacking a personal level that might have improved efficiency from the onset [23].

\section{Conclusion}

The need for faster time to market, lower costs, greater innovation and talent has brought forth the concept of virtual teams as a solution but for organizations to fully take advantage of them and reap the benefits of this competitive edge potential failure points must be identified. The paper found there is evidence of a link between performance/productivity and cultural dimensions that each team member possess. As stated in the introduction, challenges appear in virtual teams in regard to cultural dimensions. However, these dimensions should not be taken individually but comparatively and as prior research shows they don't always apply to all members of a particular culture(hofstede). Furthermore, the authors acknowledge the limitations of the research due to the small number of subjects in the monitored virtual team, but we consider it representative of a multicultural virtual team as defined in the paper. When building and managing a virtual team consideration should be taken of the diverse background of the members so as to facilitate a more efficient collaboration between members. Further and more comprehensive research should be done on the topic so as to create a more complete guideline for cross-cultural virtual team management as well as for communication improvements, as such we intend to extend our study into more examples of multicultural virtual teams to strengthen our conclusions as well as to test our hypothesis, that the cultural makeup should be taken into account when forming and managing a virtual team. 


\section{References}

[1] Rezgui, Y. (2007). Exploring virtual team-working effectiveness in the construction sector. Interacting with computers, 19(1), 96-112.

[2] Acs, Z. J., \& Preston, L. (1997). Small and medium-sized enterprises, technology, and globalization: Introduction to a special issue on small and medium-sized enterprises in the global economy. Small Business Economics, 9/1, 16.

[3] Ale Ebrahim, N., Ahmed, S., \& Taha, Z. (2009). Virtual teams: A literature review.

[4] Hertel, G., Geister, S., \& Konradt, U. (2005). Managing virtual teams: A review of current empirical research. Human resource management review, 15(1), 69-95.

[5] Powell, A., Piccoli, G., \& Ives, B. (2004). Virtual teams: a review of current literature and directions for future research. ACM Sigmis Database, 35(1), 6-36.

[6] Munkvold, B. E., \& Zigurs, I. (2007). Process and technology challenges in swift-starting virtual teams. Information \& Management, 44(3), 287-299.

[7] Albrow, M. Elizabeth King, eds. 1990. Globalization, Knowledge, and Society.

[8] (n.d.). Imagining the Internet - Elon University. Retrieved August 1, 2017, from http://www.elon.edu/eweb/predictions/150/1830.xhtml

[9] Stever, H. "Guyford.(1972). Science, Systems, and Society." Journal of Cybernetics 2, no. 3: 1-3.

[10] O'rourke, K. H., \& Williamson, J. G. (2002). When did globalisation begin?. European Review of Economic History, 6(1), 23-50.

[11] Levinson, M. (2016). The box: how the shipping container made the world smaller and the world economy bigger. Princeton University Press.

[12] Varghese, N. V. (2008). Globalization of higher education and cross-border student mobility (pp. 1-34). Paris: Unesco, International Institute for Educational Planning.

[13] (n.d.). Virtual Team - Management Study Guide. Retrieved August 1, 2017, from http://www.managementstudyguide.com/virtual-team.htm

[14] Duarte, D. L., Snyder, N. T. (2006) Mastering virtual teams: Strategies, tools, and techniques that succeed. Wiley

[15] (n.d.). Advantages and Disadvantages of Virtual Teams. Retrieved August 1, 2017, from http://www.managementstudyguide.com/virtual-teams-advantages-and-disadvantages.htm

[16] Jackson, S. E., May, K. E., \& Whitney, K. (1995). Understanding the dynamics of diversity in decision-making teams. Team effectiveness and decision making in organizations, 204, 261.

[17] Snow, C. C., Snell, S. A., Davison, S. C., \& Hambrick, D. C. (1996). Use transnational teams to globalize your company. Organizational dynamics, 24(4), 50-67.

[18] Matveev, A. V., \& Nelson, P. E. (2004). Cross cultural communication competence and multicultural team performance: Perceptions of American and Russian managers. International Journal of Cross Cultural Management, 4(2), 253-270.

[19] Hughes, Everett Cherrington. The sociological eye: Selected papers. Transaction publishers, 1971.

[20] Jarvenpaa, S. L., Shaw, T. R., \& Staples, D. S. (2004). Toward contextualized theories of trust: The role of trust in global virtual teams. Information systems research, 15(3), 250-267.

[21] Watson, W. E., Kumar, K., Michaelsen, L. K. (1993). Cultural diversity's impact on interaction process and performance: Comparing homogeneous and diverse task groups. Academy of management journal, 36, 590-602.

[22] Geert, H., \& Jan, H. G. (1991). Cultures and organizations: Software of the mind. McGaw-Hill, London.

[23] (n.d.). Countries - Geert Hofstede. Retrieved August 1, 2017, from https://geert-hofstede.com/countries.html

[24] Harangus, Daniela, and Dana Codruta Duda-Daianu. "The teamwork abilities versus leadership." Annals of DAAAM for 2011 \& Proceedings of the 22nd International DAAAM Symposium, Volume 22, No. 1, ISSN 17269679 ISBN 978-3-901509-83-4, Editor B. Katalinic, Published by DAAAM International, Vienna, Austria, 2011.

[25] Cotet, Nica. "Trust and Reputation Systems in Two Online Auction and Shopping Websites from Romania and the Netherlands." Annals of DAAAM for 2012 \& Proceedings of the 23rd International DAAAM Symposium, Volume 23, No.1, ISSN 2304-1382 ISBN 978-3-901509-91-9, CDROM version, Ed. B. Katalinic, Published by DAAAM International, Vienna, Austria, EU, 2012.

[26] G.B. COTET \& A.B. BALGIU, (2017). Using a constellation of personal capabilities in defining Industry 4.0. Soft Skills, The 4th International Multidisciplinary Scientific Conference on Social Sciences and Arts SGEM 2017, www.sgemsocial.org, SGEM2017 Conference Proceedings, ISBN 978-619-7408-22-5 / ISSN 2367-5659, 24 - 30 August, 2017, Book 3, Vol 5, 649-656 pp, DOI: 10.5593/sgemsocial2017/35/S13.085

[27] Gabriela Beatrice Cotet, Beatrice Adriana Balgiu and Violeta - Carmen Zaleschi (Negrea) (2017), Assessmentprocedure for the soft skills requested by Industry 4.0, The 8th International Conference on Manufacturing Science and Education - MSE 2017 "Trends in New Industrial Revolution”, Volume 121, Article Number 07005, https://doi.org/10.1051/matecconf/201712107005, MATEC Web of Conferences 121, 07005 (2017), eISSN: 2261-236X 